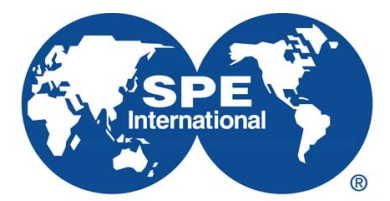

Society of Petroleum Engineers

\title{
SPE-196832-MS
}

\section{Application Rationale of Well Flow Test Complex Modules Covering Well Shut-in at the Bottomhole in terms of Eastern Siberia Carbonate Reservoirs Study}

\author{
Timur Arbatsky, Alexander Shchurenko, and Nikita Dadakin, LLC RN-KrasnoyarskNIPIneft; Marat Nukhayev, \\ Siberian Federal University; IInur Yamalov, PC «NK «Rosneft»; Konstantin Rymarenko, SIANT
}

Copyright 2019, Society of Petroleum Engineers

This paper was prepared for presentation at the SPE Russian Petroleum Technology Conference held in Moscow, Russia, 22 - 24 October 2019.

This paper was selected for presentation by an SPE program committee following review of information contained in an abstract submitted by the author(s). Contents of the paper have not been reviewed by the Society of Petroleum Engineers and are subject to correction by the author(s). The material does not necessarily reflect any position of the Society of Petroleum Engineers, its officers, or members. Electronic reproduction, distribution, or storage of any part of this paper without the written consent of the Society of Petroleum Engineers is prohibited. Permission to reproduce in print is restricted to an abstract of not more than 300 words; illustrations may not be copied. The abstract must contain conspicuous acknowledgment of SPE copyright.

\section{Abstract}

The paper presents the experience of oil and gas exploration in the fields of the Irkutsk region. The geological features of the studied facilities dictate a practical approach and the use of compact and efficient technological solutions that can later be successfully applied to a large number of fields with similar geology. The paper highlighted an optimized complex of works on the development and testing of wells target objects in a cased wellbore, using the technology of "the well shut-off at the bottomhole".

This arrangement ensures the effective implementation of work on the development of target objects and allows for high-quality registration of the bottomhole pressure dynamics. This engineering solution allows to perform a full cycle of hydrodynamical studies of well (well test) for a target interval in a relatively short time. The use of a tube bank significantly reduces the wellbore storage eand allows to obtain detailed data reliably characterizing reservoir properties and the structure of the reservoir under study.

The article describes the technology of hydrodynamic studies, with the well shut-off at the bottomhole. The article deals with the research problems of highly productive, flowing facilities, with a concrete example and a detailed analysis of technological features, interpretation options, possible complications and measures for optimization. The possibility of replicating technology in various geological and technical conditions is considered.

\section{Introduction}

Research of well test is an integral part of industrial exploration of oil and gas fields. The goal of this exploration is to obtain as complete information as possible about the structure and properties of reservoirs. It is necessary for calculating reserves and drawing up a development project, i.e. identifying the overall pattern of heterogeneity of the whole reservoir.

At the same time, the interpretation of the well test results, especially in complex carbonate reservoirs with hard-to-recover reserves, has certain difficulties.

The main reason for complicating the interpretation of pressure recovery curves (PRC) is the distortion of the radial filtration flow (IARF), which characterizes the true reservoir response. 
The reasons that complicate the identification of the radial filtration mode can be different:

- influence of constant pressure limits;

- reservoir heterogeneity;

- processes occurring in the wellbore (fluid reallocation),

- fluid influx, after stopping welldore storage

\section{Geological features of the Well test targets}

\section{Search tag for oil and gas exploration - the crystalline basement high}

Currently (2011-2019), a promising direction for geological exploration in the license areas of the Irkutsk Region is the location and drilling of wells in the "paleo-high / remnants" circuit of the crystalline basement. The zones of secondary transformation / leaching of carbonate sediments of the Lower Cambrian age, mainly represented by dolomites, are confined to this.

The general geological concept of the productive zones extent implies lateral localization of a reservoir with relatively small effective volumes (Figure 1).

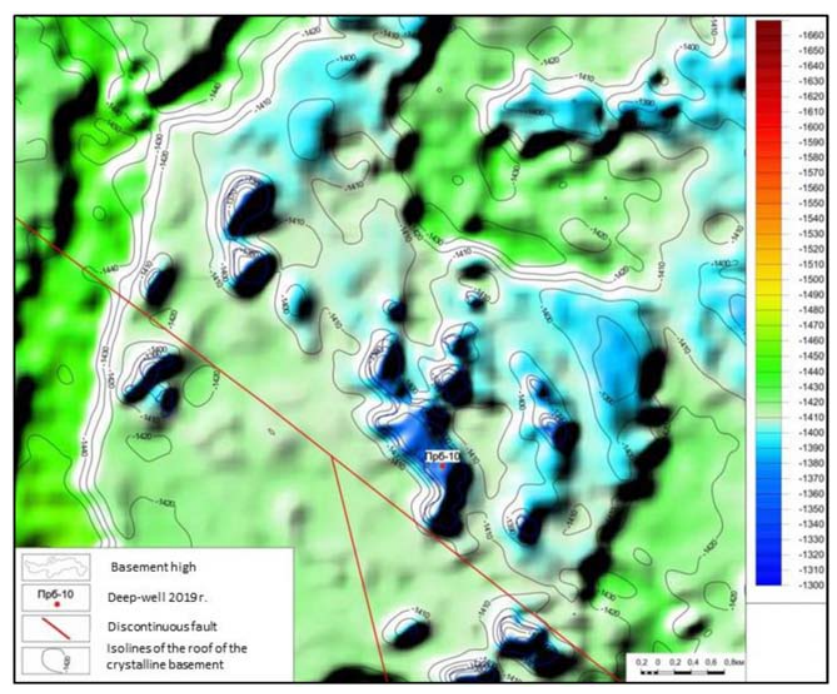

Figure 1-Structural map of the crystalline basement roof.

The above approach is confirmed by the results of hydrodynamic studies of testing and exploration wells, as well as by more lengthy studies during the trial operation of oil and gas condensate deposits.

The geometrization of reservoirs according to well test data is consistent with seismic data, for which the area of productive zones may be less than $1 \mathrm{~km}^{2}$.

According to the results of geophysical studies of wells and laboratory studies of the core sample, the reservoir is characterized as a cavernous-pore, with a complex structure of voids.

Relatively high phase, weighted average permeability of the reservoir (in the range from 0.1 to 2 Darcy, with oil saturated thickness of 15-20 m, dynamic oil viscosity $-1.5-3 \mathrm{MPa} * \mathrm{~s}$ ), mainly related to the intervals of intensive leaching / cavern formation (Figure №2). 


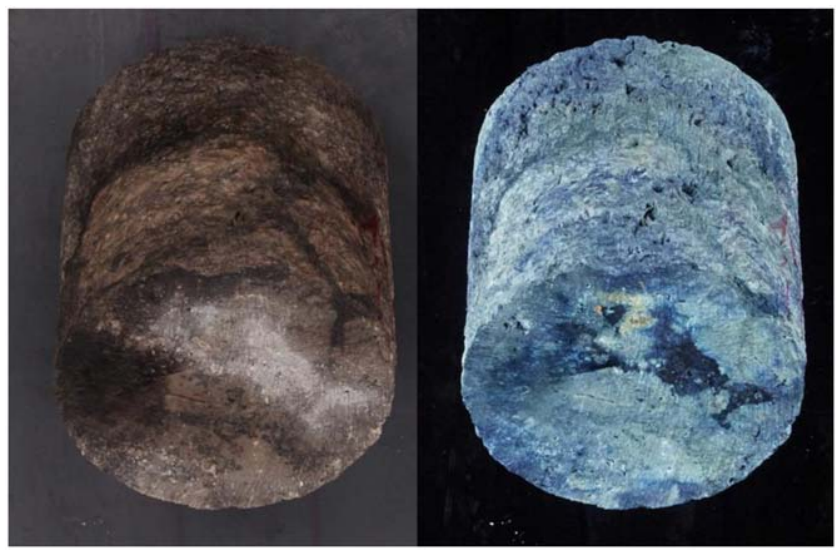

Figure 2-Photographs of a carbonate reservoir core from a well drilled over a basement high in daylight and ultraviolet light.

Currently, there is no single, detailed solution to the problem of the hydrodynamic mechanism of mass transfer and filtration in a cavernous-pore reservoir and the principle of its vertical range. However, it is clear that it is necessary to focus attention in the direction of research on the effects of double voidness.

\section{Search tag for oil and gas exploration - reefal buildup.}

According to the regional geological concept, in the northern part of the Irkutsk region (the western slope of the Nepsko-Botuobinsky anteclise), a massive reef barrier is distinguished.

At the current time, wells have been drilled and explored, revealing reef structures. These geological bodies have high effective capasity $(30-50 \mathrm{~m}$ ) and permeability (from 0.1 to 3 Darcy), however, they are localized laterally (Figure 3).

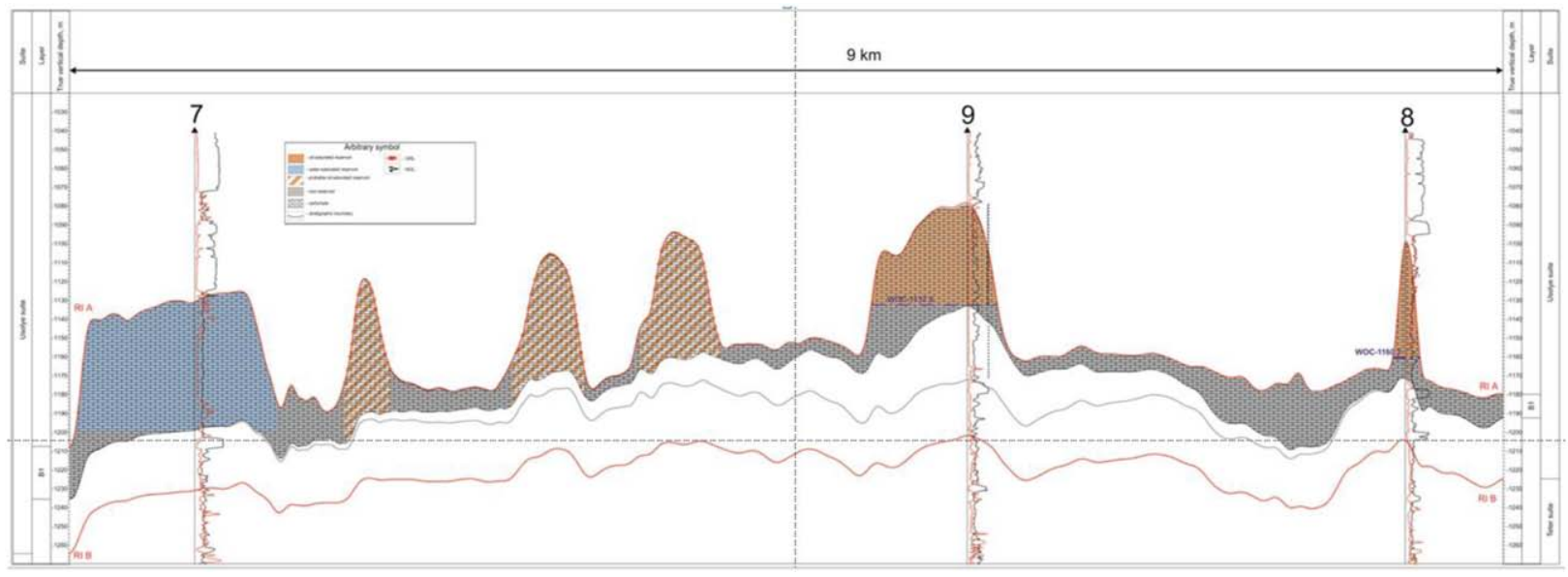

Figure 3-Geological section along the line of wells drilled on reefal buildup.

According to the results of testing prospecting and exploration wells, the minimum equivalent radius of the well drainage (to the reservoir boundary) was about 350 meters.

According to the data of geological objects of the reefal type, the type of reservoir has a complex void space and is classified as fracture-cavernous.

\section{Complicating factors during well test}

An important geological task of drilling prospecting and exploration wells, along with geophysical studies, sampling of core material, sludge, is a qualitative, informative hydrodynamic study of reservoir systems. 
However, at the stage of exploration, in conditions of limited testing time, as well as insufficient technical equipment, it is difficult, and in some cases it is impossible to obtain qualitative data.

To compile statistics of well test informativeness, the authors considered oil facilities with flowing wells.

According to the results of the analysis of hydrodynamic studies of oil facilities in the licensed areas of the Irkutsk region, there are two main complicating factors:

1. Influence of geological localization of the studied reservoirs;

2. Showing of segregation processes in the wellbore.

Research of the oil facility in unsteady filtration modes (PRC), characterized by a substantially-localized reservoir volume, in conditions of high piezoconductivity of the reservoir and a long period of the wellbore storage leads to leveling of the radial filtration mode by the influence of the reservoir boundaries. Also, with showing of segregation processes (fluid reallocation processes), during early and middle well test period, the true response of the reservoir system may be hidden.

When the above factors appear during hydrodynamic study process, there can be uncertainty in assessing such key parameters as:

- Lateral permeability;

- Initial reservoir pressure;

- Parameters of "double void".

Without identification of such key parameters at the stage of oil and gas exploration, the question of the success / informativeness of the research as a whole is raised (Figure 4).
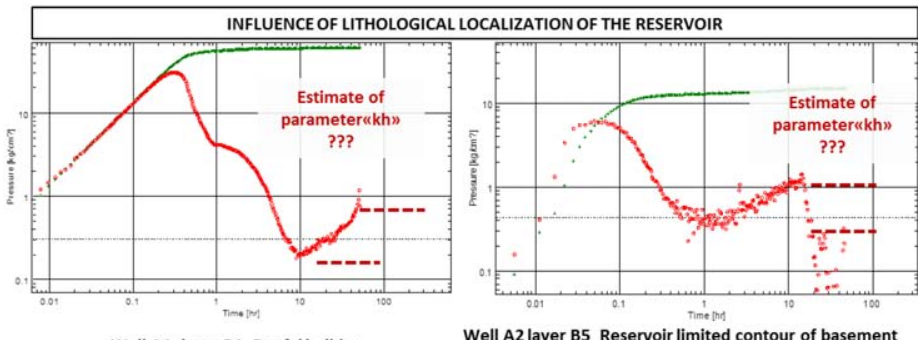

Well A1_layer B1_Reefal buildup

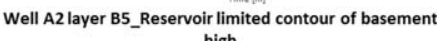

high

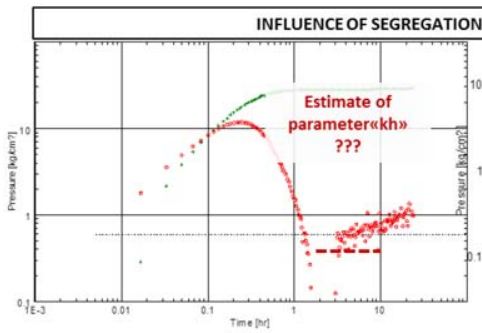

Well A3 layer B12_Well test with completion GOC

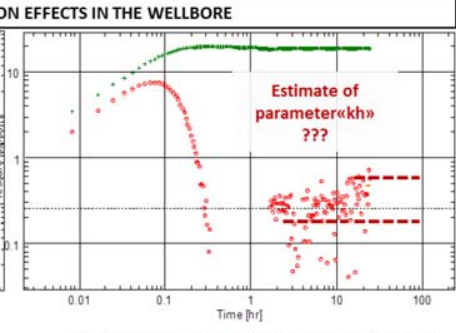

Figure 4-An example of the complicating factors of localization and fluid reallocation in the wellbore, during hydrodynamic studies on unsteady filtering modes (log-log coordinates).

\section{Methods to minimize negative factors}

The scheme below (Figure 5) presents the matrix of the approach to regulating and minimizing complicating factors. 


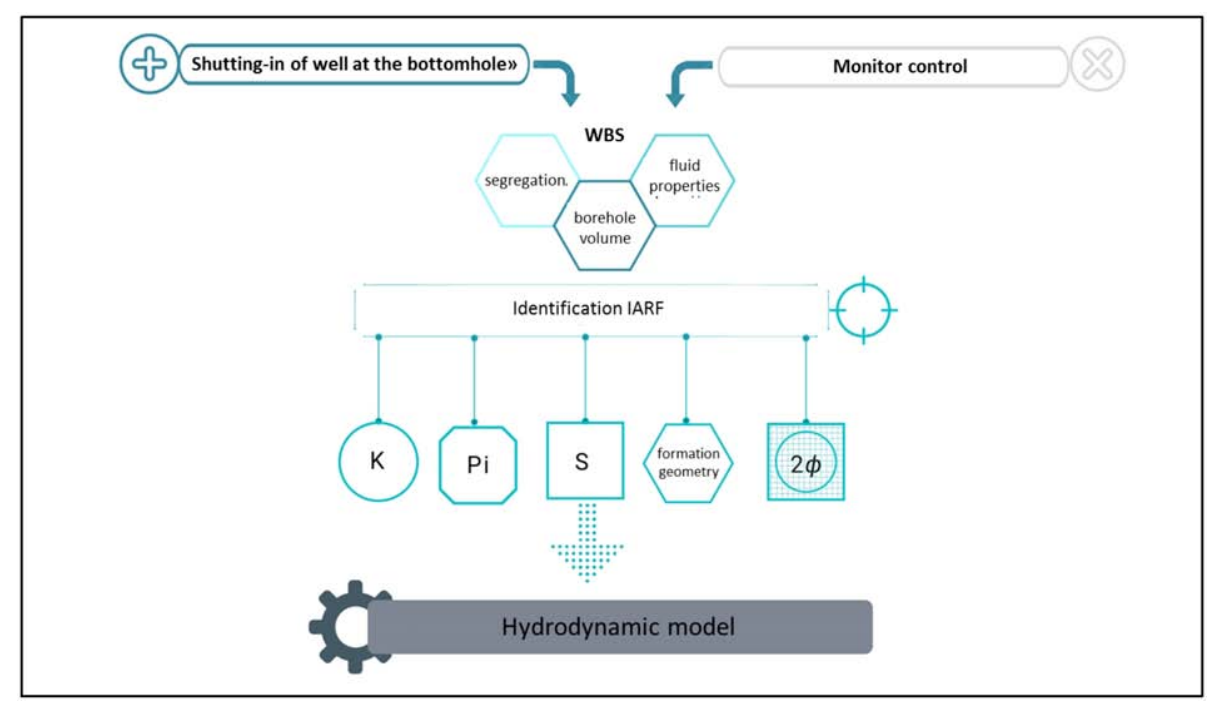

Figure 5-The matrix approach to the regulation and minimization of complicating factors in hydrodynamic study on unsteady filtering modes.

Based on the presented scheme, it can be seen that, while studying reservoirs by the method of recording PRC / PSC, identification of signs of the radial mode is the target task, since the determination of such key parameters as permeability, reservoir pressure and skin-factor depends on the reliability of diagnosing this flow pattern. In addition, it should be noted that the piezoconductivity of the studing system directly depends on the quality of the permeability assessment, on which, in turn, the geometrization of the reservoir will depend.

The lack of identification of key parameters at the stage of geological exploration raises a serious question about the success of the research as a whole. It significantly reduces the possibilities of hydrodynamic modeling.

Based on the presented matrix, it follows that the only parameter that can be influenced during hydrodynamic study and which can significantly increase the information content of the research is the period of influence of wellbore storage.

The authors emphasize that the traditional approach to the research time increment is not effective, not only from an economic point of view, but also from a geological one. This circumstance, as mentioned above, is associated with the target facilities feature. During the research, under conditions of high piezoconductivity of a reservoir and a long period of wellbore storage, the radial mode is leveled by the influence of reservoir boundaries.

The issue of the influence of wellbore "parasitic" capacity has received much attention from the very beginning of the creation of well test methods interpretation. The first works that were devoted to hydrodynamic studies of wells (van Everdingen, A.F., Hurst, W., 1949) showed that the time to reach the radial flow regime directly depends on the value of the wellbore capacity.

In 1958, Stegemeier and Matthews (Stegemeier, G.L., Matthews, C.S., 1958) for the first time ever proposed the concept of fluid phases reallocation in the wellbore. They proved that these phenomena occur in wells that are closed at the mouth. They also noted that this effect is caused by the simultaneous filtration of gas and liquid in the wellbore. It should be said that Matthews and Russell (Matthews, C.S., Russell, D.G., 1967) considered the phases reallocation in the wellbore as a noticeable and unusual behavior of bottomhole pressure, but they did not write about the physicochemical mechanism of this effect and did not offer any interpretation technique.

In the future, this idea was developed in the works of Fair and Hageman. In 1981, Fair (Fair Jr., W.B., 1981) proposed a model that can be solved in the Laplace space and which takes into account phase 
reallocation in the wellbore. Later, in 1991, Hageman (Hegeman, P.S., Hallford, D.L., Joseph, J.A., 1991) in his work modified the Fair's analytical solution.

The influence of the "afterflow" and segregation processes in the wellbore on the reliability of the information obtained during hydrodynamic studies was considered by many authors in Russian literature. Of particular interest is the work of Buzinov and Umrikhin (Buzinov, S.N., Umrikhin I.D., 1984). Buzinov and Umrikhin also noted that the bias of the initial plots due to the "after flow" leads to the fact that the initial plots that carry information about the bottomhole zone are defective (Arbatskii T.S., Shchurenko A.A. 2018).

During hydrodynamic studies on unsteady filtration modes, the well is closed at the mouth in most cases. Thus, the wellbore always divides the bottomhole and the mouth with the volume $\mathrm{V}$, it causes the pressure change to lag over the time between the bottomhole and the mouth. After the well shut-off at the mouth, the bottomhole pressure changes (growth) with time and the reservoir fluid continues to flow into the wellbore due to the hole capacity and compression of the gas-liquid mixture in the wellbore (increase in density). At the same time, as the pressure in the wellbore increases, the intensity of this effect decreases. This effect is called a wellbore storage. The storage effect is shown schematically in the figure below (Figure 6).

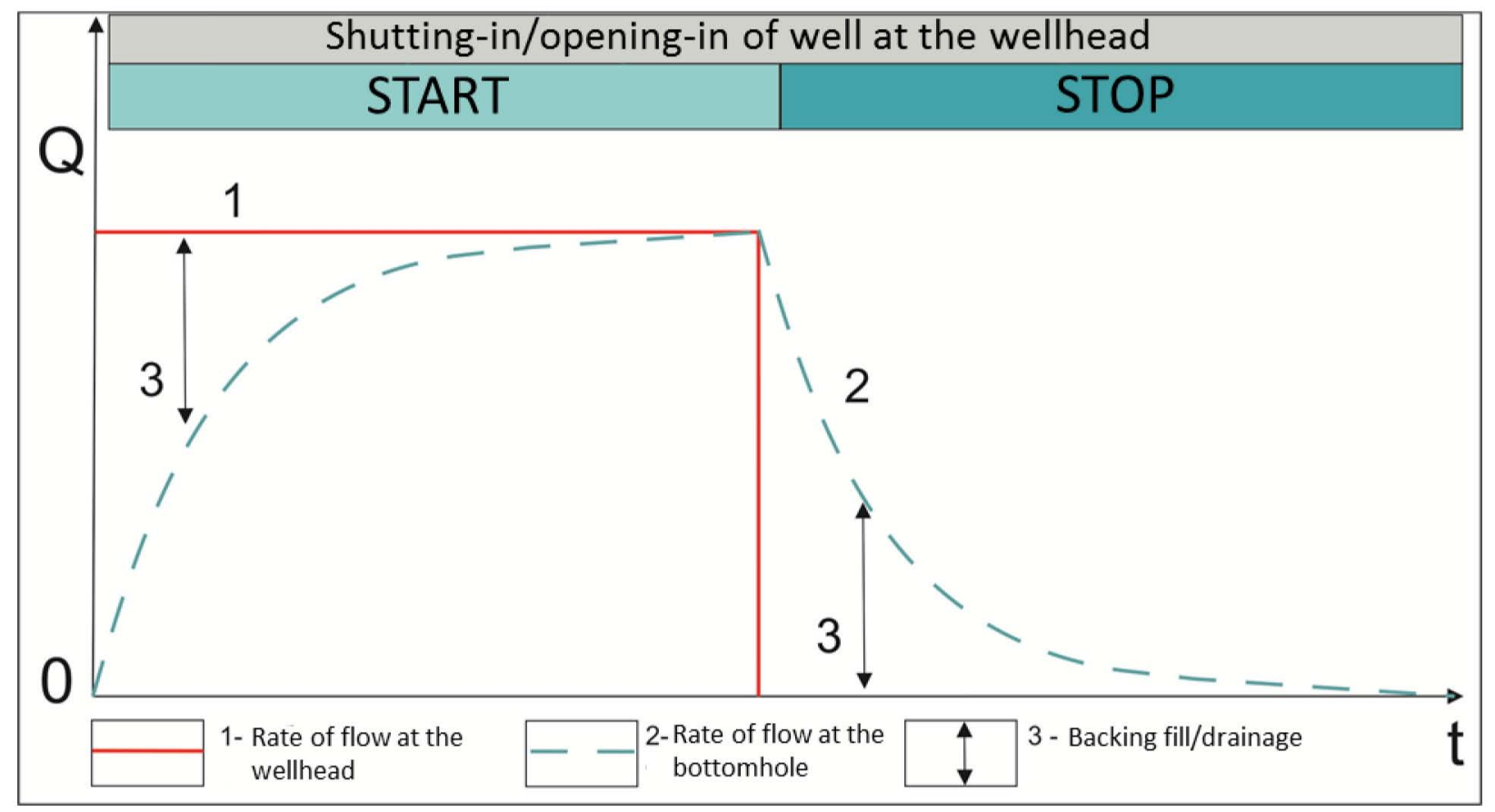

Figure 6-The storage effect in the study of the flowing wells on the technology: PRC-PSC.

This effect depends on the wellbore capacity, the changing level of fluid in the wellbore, the compressibility of the fluid and is expressed through the formula:

$$
\mathrm{C}=\frac{\Delta \mathrm{V}}{\Delta \mathrm{P}}
$$

where $\Delta \mathrm{V}$ is the change of the fluid volume reduced to the temperature and pressure conditions in the wellbore at the beginning of the flow, $\Delta \mathrm{P}$ is the change of pressure in the well, after stopping during time $t$.

The ratio for estimating the afterflow coefficient, due to the fluid compressibility, can be obtained from the following considerations. From the formula for calculating the compressibility coefficient of the filling fluid, with the initial volume V:

$$
\beta f=\frac{1}{\mathrm{~V}}\left[\frac{\mathrm{dV}}{\mathrm{dP}}\right]
$$


Accordingly, fluid compression or volume reduction obeys the following equation:

$$
\Delta V=\beta f^{*} V^{*} d P
$$

Where $\beta \mathrm{f}$ is the fluid compressibility in the wellbore, $\mathrm{V}$ is the initial volume, $\mathrm{dP}$ is the pressure change.

Based on the foregoing, it follows that the main parameters determining the magnitude and duration of the wellbore storage are the volume of the wellbore $\mathrm{V}$ and the compressibility of the reservoir fluid. This fact suggests that the only methods of influence on the duration of the wellbore storage period, and on improving the quality of research, are:

1. Adjustment of the operation mode prior to well test- the effect on the parameter of fluid compressibility, i.e. change of thermobaric conditions in the wellbore, after closing. This chsnge allows reducing the effect of the gas phase on the overall the fluid compressibility.

2. The use of technology research, with the killing of the well at the bottom - cut off "parasitic volumes" by closing the well at the bottom.

Note that the regulation of the operation mode before the well stops only slightly reduces the wellbore storage. The technology of well shut-off at the bottomhole will allow improving the quality and informativeness of hydrodynamic research.

As mentioned above, in the presented work a large data array was analyzed. For the compilation of a statistical database and subsequent analysis, oil facilities with flowing wells were considered. Facilities with gas saturation were not considered, due to technological risks. And there is an alternative of using jet pump installations for hydrodynamic study of non-flowing facilities.

The total sample and the number of studies is 20 hydrodynamic studies from 14 wells.

According to the results of the analysis, it can be concluded that $30 \%$ of studies of oil facilities are unsuccessful and uninformative (the 2 nd group), due to the influence of complicating geological factors (Figure 7). We name the "factor of reservoir localization"as a predominant one.

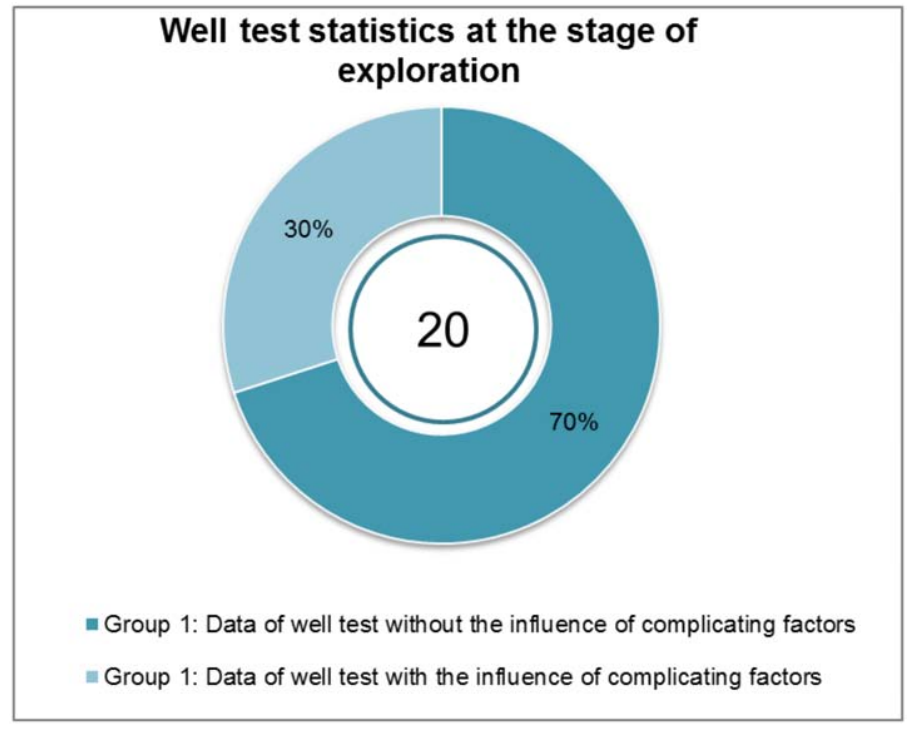

Figure 7-General statistics of research informativeness, ranking by selected complicating factors.

The main candidate facilities that are under this factor of influence are high-productive reservoirs. There boundaries are identified immediately after the afterflow period (wellbore storage), during hydrodynamic studies. 
Based on Ramey's empirical regularity (rule of thumb), it is necessary for correct diagnosis of the radial flow mode that the interval [ $\left.\mathrm{t}_{\mathrm{wbs} \text { end; }} \mathrm{t}_{\mathrm{IARF} \text { end }}\right]$ is at least $0.5-1$ logarithmic cycle. Graphically, the Ramey's rule can be represented by plotting the bottom hole pressure change in log-log coordinates (Figure 8).

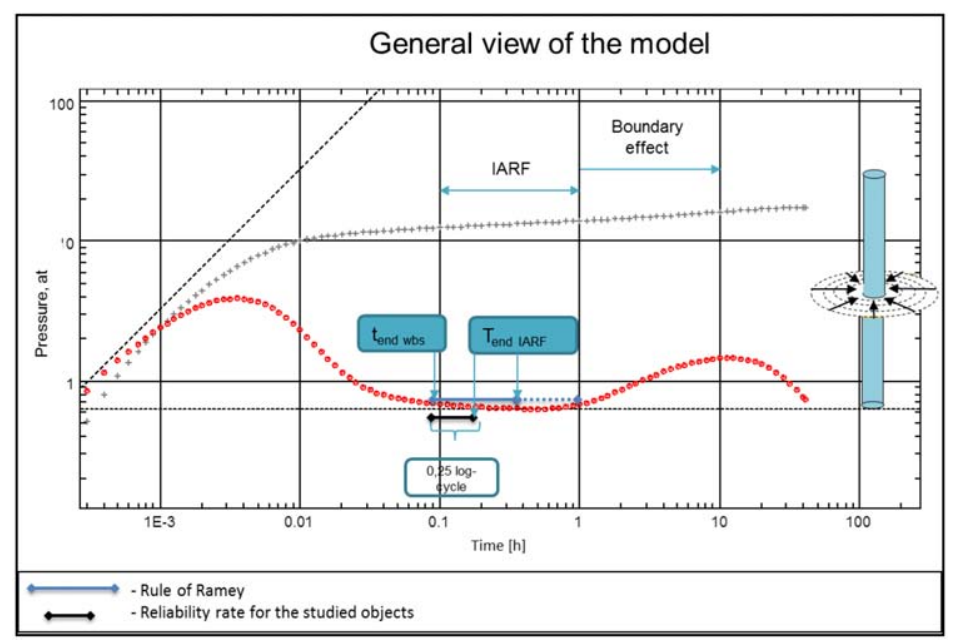

Figure 8-Diagram of a quality well test

According to the authors' experience, for correct diagnosis of the radial flow mode, it is necessary that the interval [ $\mathrm{t}_{\mathrm{wbs} \text { end }}$; $\left.\mathrm{t}_{\mathrm{IARF} \text { end }}\right]$ is not less than 0.25 logarithmic cycle.

The analysis shows that the duration of the dominance of the radial filtration mode is less than 0.25 logcycle. It does not march the basic standards for the reliability of reservoir properties assessment for the studied facilities. At the same time, the minimum coefficient of Cs wellbore storage, determined by the combined analytical models of PRC, is $0.408 \mathrm{~m}^{3} / \mathrm{MPa}$ (maximum $2.48 \mathrm{~m}^{3} / \mathrm{MPa}$ ) (Figure 9).

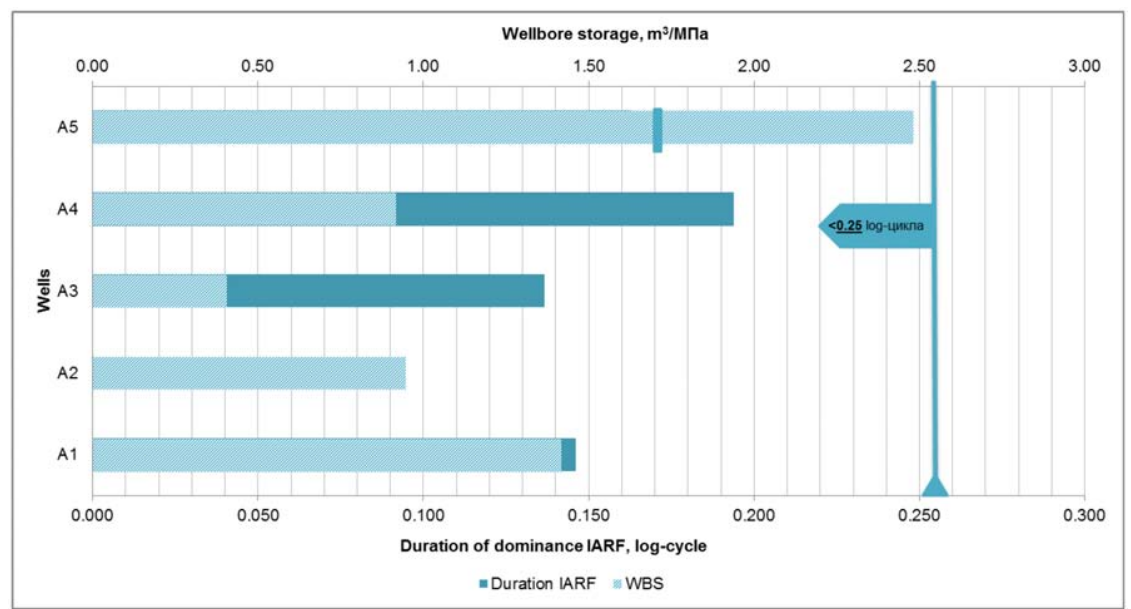

Figure 9-The duration of the wellbore storage period and the Cs value of the 2 nd group of wells

The above criterion in the study, with the influence of such a complicating factor as segregation, can lead to a false identification of the "plateau of IARF", which is actually an artifact and a non-reflective true response of the reservoir hydrodynamic system.

In the figure (Figure 10), the authors give an example of a research where the incorrect detection of the radial mode on the Bourdet derivative graph leads to an underestimation of permeability by more than $60 \%$ (260 mD vs. $700 \mathrm{mD})$. 


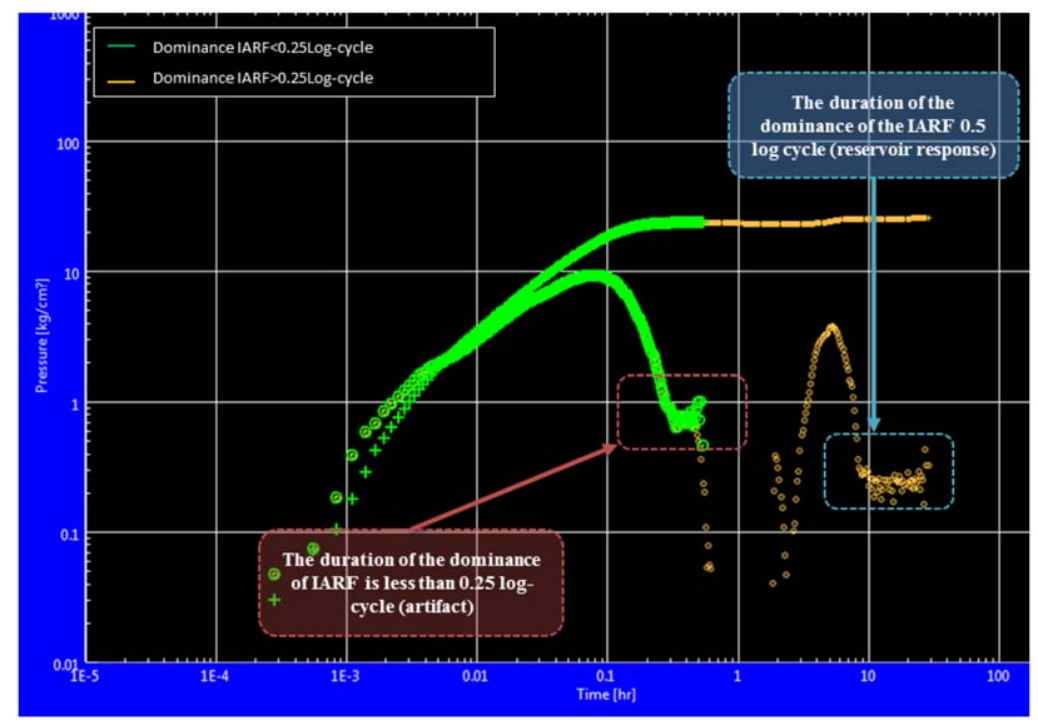

Figure 10-An example of false identification of radial filtration mode

Accordingly, the possibility of obtaining the reservoir properties in the address well conditions can be determined from the following inequality:

$$
\mathrm{T}_{\text {IARF }}=\mathrm{t}_{\mathrm{IARF} \text { end }}-\mathrm{t}_{\mathrm{wbs} \mathrm{end}}>0.25
$$

Where $t_{\text {IARF }}$ is the duration of the radial filtration mode, $t_{\text {IARF end }}$ is the end of the radial filtration mode, $\mathrm{t}_{\mathrm{wbs} \text { end }}$ is the end of the afterflow period dominance.

Thus, it becomes obvious to apply the technology of well bottomhole closure, which will allow for reliable identification of the radial filtration mode at early research periods, which is hidden by the wellbore storage without this technology.

\section{Considered technological solution}

The authors propose a solution aimed at reducing the "working capasity" of the well to minimize the risks of hydrodynamic study. Because there is the influence of complicating factors of lateral localization of the studied facility.

When considering the study of highly productive, oil, flowing facilities, the standard set of the downhole and wellhead equipment implies large "wellbore working capasity". By working capasity it is meant the shank bore of the production casing from the top of the test interval to the mouth.

If we take into account that the depth of the target facilities of the hydrodynamic study is about 1,500 $1,600 \mathrm{~m}$, the "working capasity" of the wellbore is $25-26 \mathrm{~m}^{3}$, without a liner string $28-29 \mathrm{~m}^{3}$, if the liner string is lowered. In this case there will be a complicating "afterflow" factor, leveling the true pressure response of the reservoir system, during hydrodynamic studies on steady-state and unsteady filtration modes, with regulation on the mouth.

Currently, many Russian oil companies are widely practicing the technology of the well closure at the bottomhole, when testing formations with jet pump installations. However, this technology is applicable for non-flowing facilities and has a number of technical limitations.

The authors propose a closure at the bottomhole, which is in many respects similar to the layout of the jet pump, however the pipe packer is the key distinguishing element (Figure 11). 


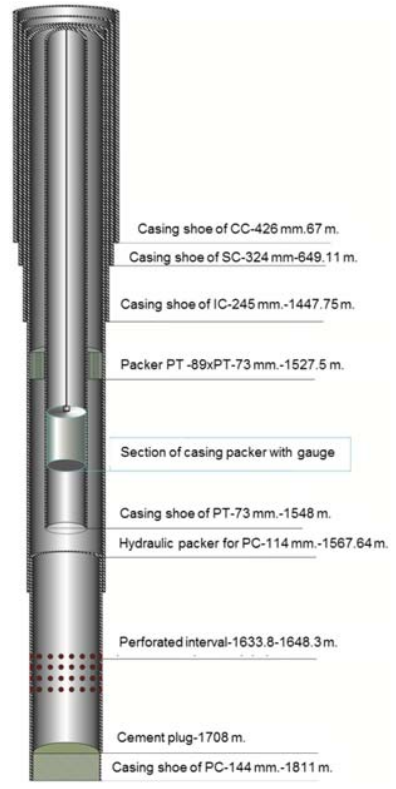

Figure 11-Schematic layout of the hydrodynamic research downhole equipment, involving the closure of the well at the bottom (casing packer).

In this case, external packers (or analogs) cut off the annular space of the casing column, and the casing packer uncouples the cavity of the oilwell tubing elevator. The elevator goes down the well on the armored geophysical cable. The main parameters / dimensions of the considered complex module of the casing packer are presented in the table below (Table 1).

Table 1-Basic characteristics of the complex module

\begin{tabular}{|c|c|c|c|}
\hline Modules & $\begin{array}{c}\text { Length of modules, } \\
\mathrm{mm}\end{array}$ & Module weight, $\mathrm{kg}$ & Outer diameter, $\mathrm{mm}$ \\
\hline Telemetry module & 2305 & 22 & \multirow{2}{*}{5} \\
\hline Anchor module & 1292 & 16 & \multirow{2}{*}{54} \\
\hline Packer module & 1360 & 16 & \\
\hline Manometer module & 576 & 6.5 & \\
\hline Complex assembly & $\mathbf{5 5 3 3}$ & $\mathbf{6 0 . 5}$ & \\
\hline
\end{tabular}

A reduction in the "wellbore working capasity" is achieved by more than $70 \%$ during wells testing that provide the above layout of well equipment (Figure 12). 


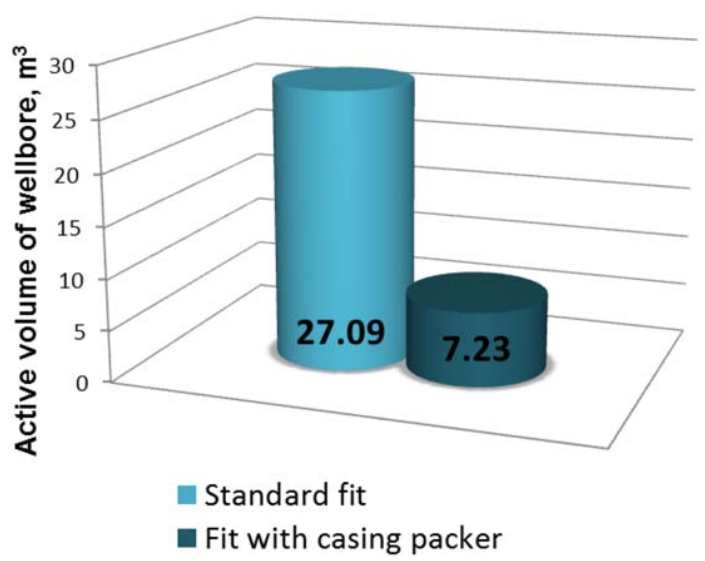

Figure 12-Comparison of the "wellbore working capasity" with the standard and proposed equipment layout.

According to the results of testing this technology in 2018, it should be noted the disadvantage associated with the difficulty of transporting the module of the casing packer to the target depth during the flow of a well (Figure 13).

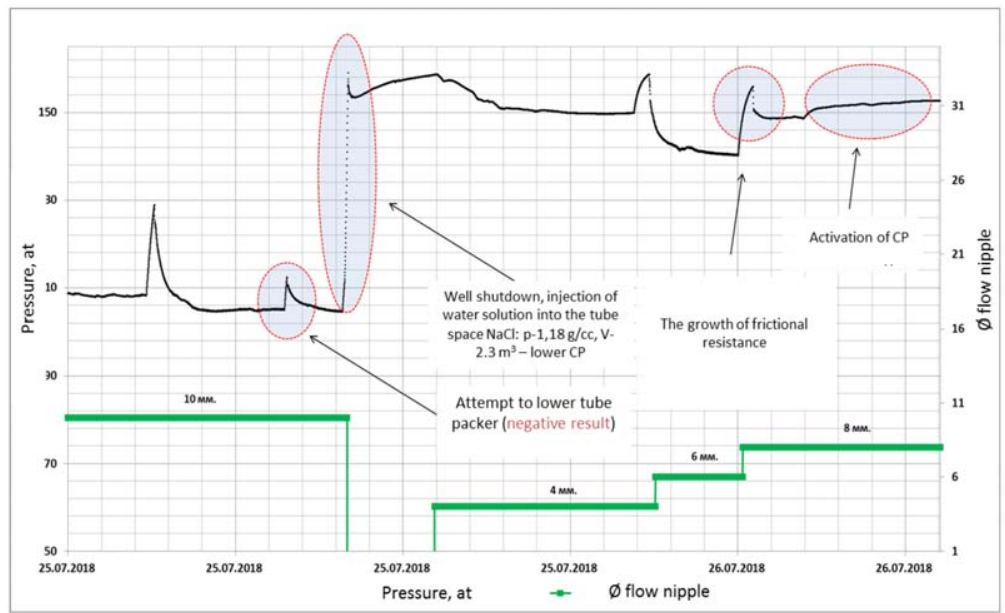

Figure 13-Operational algorithm of setting the casing packer layout before stopping the well for the PRC registration.

The difficulty lies in the fact that during the setting of the casing packer module on the geophysical cable (its outer diameter is $54 \mathrm{~mm}$ with a mass of $60.5 \mathrm{~kg}$ (deactivated state), the upward flow of the gasliquid mixture "pushes out" the casing packer module in the oilwell tubing with an inner diameter of 62 $\mathrm{mm}$ (Figure 14).

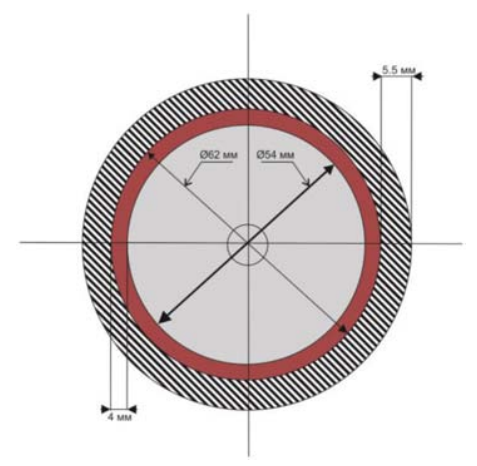

Figure 14-Section of the oilwell tubing and casing packer. 
The reason for the complications of transporting the casing packer module is the small annular gap (4 $\mathrm{mm}$ ) between the module case and the inner walls of the oilwell tubing. Taking into account the above facts, before the launching and activation of the module, it is necessary to choose the well operation mode with minimal flow rates. It will reduce frictional pressure loss.

\section{Replication of Technology, in Order to Improve the Quality and Informativeness of Geological Research}

In the study of geological objects considered by the authors, which are characterized by lateral localization of the reservoir, some useful information, and often the basic hydrodynamic parameters can be estimated not reliably. Due to the dominance of fluid reallocation processes in the wellbore and a long afterflow period, the standard layout of the downhole pumping equipment of the studied well requires technical optimization aimed at reducing working capasity, so that it will be possible to minimize the bore hole effect.

As an example, the authors present a possible scenario of hydrodynamic studies with the variability of the wellbore storage coefficient, which shows the possible underestimation of the hydrodynamic reservoir parameters in a research with a standard layout.

The figure above (Figure 15) shows cases of research with underestimation of such key parameters as permeability and identification of double voidness, characteristics of these geological objects.

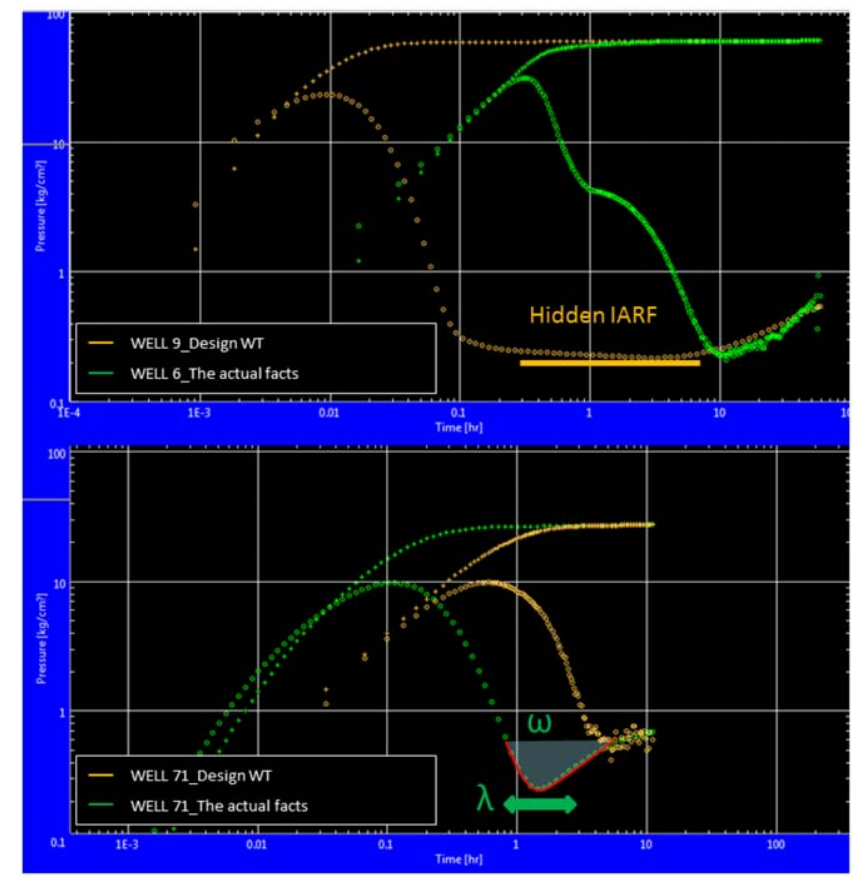

Figure 15-Scenario of hydrodynamic studies with the variability of the wellbore storage coefficient, reflecting the underestimation of the reservoir parameters.

For the compilation of research designs with the closure of a well at the bottomhole, the main parameter affecting the overall quality and duration of the study is the wellbore storage coefficient.

General analysis shows that the duration of the dominance of the radial filtration mode is less than 0.25 log-cycle. It does not match the basic standards for the reliability of the reservoir properties (the rule of thumb is at least 0.5 ). The minimum wellbore storage coefficient, determined by the combined analytical PRC models, is $0.408 \mathrm{~m}^{3} / \mathrm{MPa}$ (maximum 2.48).

With the test use of the well shut-off technology at the bottom in 2018, the wellbore storage coefficient was $0.125 \mathrm{~m}^{3} / \mathrm{MPa}$, which is significantly lower than with the hydrodynamic study with a standard layout (Figure 16) 


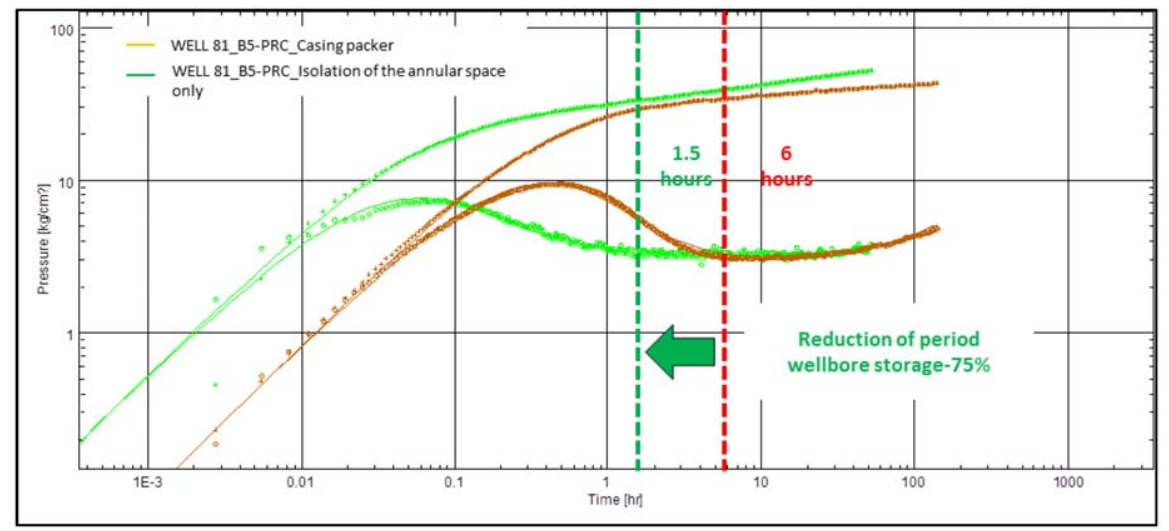

Figure 16-Comparison of Bourdet derivative diagnostic graphs PRC-1 (with packer) and PRC-2 (without packer)

Based on the actual study graphs, reducing the working capasity of the well by $73 \%$ (from 27.09 to 7.23 $\mathrm{m}^{3}$ ) helps to reduce the non-informative study period - "afterflow" whitch levels the true reservoir response.

In order to evaluate the real efficiency in the complicated conditions of the geological objects research, the authors give an example of the localized reservoir research, with the translation of the wellbore storage coefficient determined according to experimental data in 2018 (Figure 17).

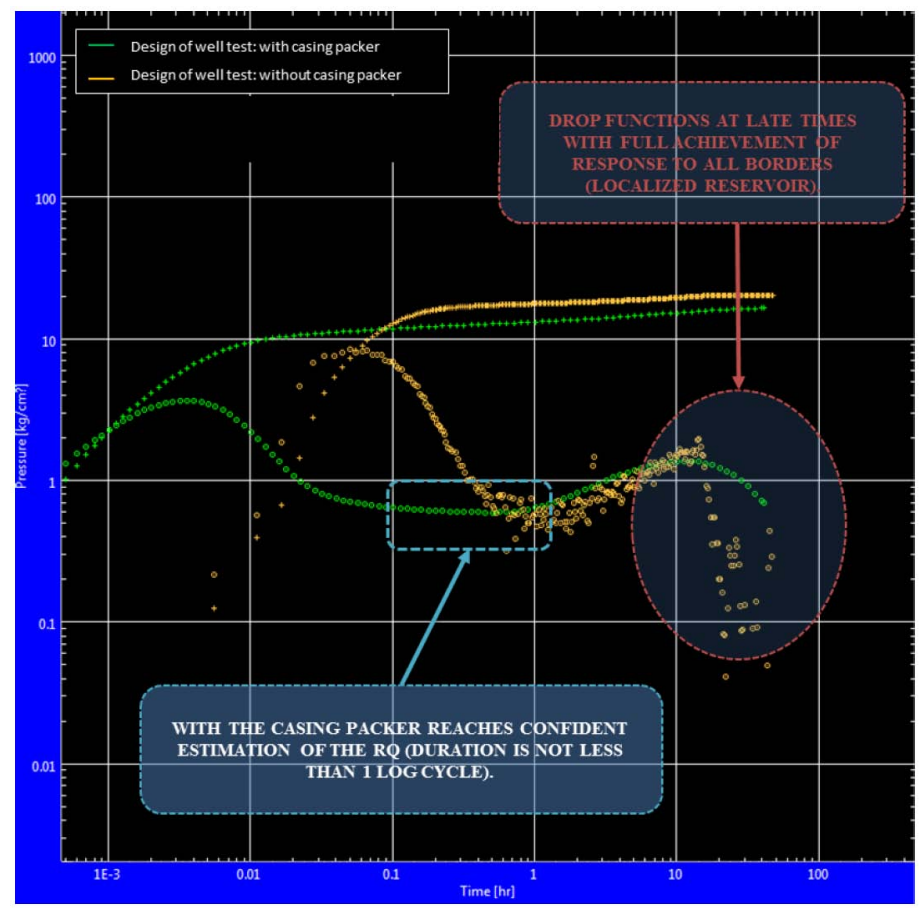

Figure 17-Test-design of hydrodynamic studies to compare the standard technology and the technology of well shut-off at the bottom.

In the study of localized reservoirs with high piezoconductivity, it is sometimes not possible to estimate the lateral permeability of the reservoir, since all diagnostic signs are hidden by the influence of boundaries. The proposed studing technology will allow the reliable identification of the radial filtration mode (it is usually hidden by the wellbore storage) at early stages of the study.

\section{Conclusion}

The technology, including: technical and technological aspects of the proposed method, was analyzed. 
The layout of the submersible equipment, adaptive for different geological and technical work conditions; simulation of research scenarios, implying the reservoir properties of the studied reservoir, was carried out.

The substantiation of the effectiveness of the technology is given. This technology allows to increase the information content under the conditions of complicating factors: long-term dominance of the wellbore storage period; the influence of the boundary effects of lithological or tectonic localization of the studied geological bodies.

According to the results of hydrodynamic studies analysis of oil facilities in the study area, there are two main complicating factors:

1. Influence of geological localization of the studied reservoirs;

2. Showing of segregation processes (fluid reallocation processes) in the wellbore.

With showing of the above factors in the process of hydrodynamic study, there is uncertainty in the assessment of such key parameters as:

- lateral permeability;

- nitial reservoir pressure;

- double void rating.

Based on the results of the analysis, it can be concluded that $30 \%$ of studies of oil facilities are unsuccessful / uninformative, due to the influence of complicating geological factors.

To increase the information content and reduce the total research time, it is recommended to consider the hydrodynamic study technology with well shut-off at the bottomhole.

The research technology with well shut-off at the bottom will allow reliable identification of the radial filtration mode in the early research periods, which, without the use of this technology, is hidden by the bore hole effect.

There are geological features of the studied reservoir in Eastern Siberia, in particular, the fields of the Irkutsk region, which are characterized by lateral localization (reefal type areas, local productive zones above the crystalline basement high). The use of special technological complexes will make it possible to increase the information content and quality of hydrodynamic studies at the stage of geological exploration in the region. Using the recommended well shut-off at the bottom technology during testing exploration and exploratory wells are not a technically challenging solution. However an increase in informativity will increase the success of exploration in general and help to remove uncertainties in the design of complex carbonate reservoirs in Eastern Siberia.

\section{Bibliography:}

Bourdet, D.W, 2003. Well Interpretation Models.

Bourdet, D.W., Douglas, A.A., Pirard, Y.M., 1983. A new set of type curve simplifies well test analysis. World Oil, 95-106 (May).

Bourde D.W., 2002. Well Test Analysis: the Use of Advanced Interpretation Models, 461. Elsevier science. Amsterdam, Netherlands.

Baikov VA, Emchenko OV, Zainulin AV, Davletbaev A.Ya., 2007. Interpretation and analysis of the results of investigations of the reservoir of a crack-cavernous-pore type. Scientific and Technical Herald of OJSC "NK" Rosneft", No. 5: 30-34.

Belonovskaya L.G., 2006. Fracture of carbon rocks and the foundations of the search for fractured reservoirs of oil and gas developed in VNIGRI. Petroleum geology. Theory and practice: 9-13.

Deeva T.A., Kamartdinov M.R., Kulagina TE, Mangazeev P.V., 2009. Well test: analysis and interpretation of data, 243.Tomsk: TPU Publishing House.

Earlaugher R.C. Jr., Kerch K.M., 1974. Analysis of short-time transient test data by type-curve matching. Journal of petroleum technologies, V 26: 793-800. 
Fair Jr., W.B., 1981. Pressure buildup analysis with wellbore phase redistribution. Soc. Pet. Eng. J., 259-270 (April). Gringarten A.C., 2012. Well Test Analysis in Practice. The way ahead. SPE-0212-010-TWA: 10-15.

Hegeman, P.S., Hallford, D.L., Joseph, J.A., 1991.Well test analysis with changing wellbore storage. SPE Form. Eval., 201- 207 (Sept.).

Horne R.N., 1990. Modern Well Test Analysis. A computer Aided Approach, 185. Petroway Inc. US.

Houze O., Viturat D., Fjaere O.S., 2011. Dynamic Data Analysis v4.12.02, 557. Kappa

Matthews, C.S., Russell, D.G., 1967. Pressure buildup and flow tests in wells. SPE Monograph Series, vol. 1, Richardson, TX, p. 27.

Olarewaju, J.S., 1990. Detection and interpretation of well test data distorted by phase segregation. J. Pet. Sci. Eng. 5, 201-212.

Olarewaju, J.S., Lee, W.J., 1989a. Effects of phase segregation on buildup test data from gas wells. SPE 19100, Gas Technol. Symp., Dallas, TX, USA.

Olarewaju, J.S., Lee, W.J., 1989b. Pressure behavior of layered and dual-porosity reservoirs in the presence of wellbore effects. SPE. Form. Eval., 397-405 (Sept.).

Stegemeier, G.L., Matthews, C.S., 1958a. A study of anomalous pressure build-up behavior. J. Pet. Technol., 44-50 (Feb.). Stegemeier, G.L., Matthews, C.S., 1958b. A study of anomalous pressure build-up behavior. Trans., AIME 213, 75-81.

Van Everdingen, A.F., Hurst, W., 1949. The application of the Laplace transformation to flow problems in reservoirs. Trans., AIME 186, 305-324.

Xiao, J.J., Fuentes-N, F.A., Alhanati, F., Reynolds, A.C., 1995. Modeling and analyzing pressure buildup data affected by phase redistribution SPE 26965. SPE Adv. Technol. Ser., 28-37.

Shchurenko A.A., Arbatskii T.S., et al. 2018. Features of the well test interpretation in complicated conditions of intensive segregation of phases in the wellbore and the manifestation of the effects of abnormal pressure growth. Paper SPE -191561 presented at the RPTC SPE, Moscow, 22-24 October. SPE-191561-18RPTC-MS. 